\title{
POSSIBILITIES OF IMPROVING THE SHEAR STRENGTH BETWEEN DIFFERENT TYPE OF CEMENT AND ZIRCONIA CERAMICS: LITERATURE REVIEW
}

\author{
Ivan Gerdzhikov ${ }^{1}$, Elka Radeva ${ }^{2}$, Todor Uzunov ${ }^{1}$ \\ 1) Department of Prosthetic Dentistry, Faculty of Dental Medicine, Medical \\ University - Sofia, Bulgaria \\ 2) Department of Conservative Dentistry, Faculty of Dental Medicine, Medical \\ University - Sofia, Bulgaria.
}

\begin{abstract}
Background: Zirconia ceramics are a modern dental material which has a wide range of application in restoration of frontal and distal teeth. This is due to its improved mechanical properties and aesthetics.

Aim: This literature review analyses the possibilities for improvement of the bond strength between zirconia ceramics and different types of cement which are used for fixation of prosthetic constructions.

Review Results: The evidence from the literature indicates that preliminary treatment of zirconia ceramics increases the bond strength significantly to the cement. In this respect, different methods and materials are used for the treatment of the zirconium dioxide surface. Some of them include only mechanical treatment with diamond burs, a different type of lasers and sandblasting with aluminum oxide. Other methods have chemical action by the use of hydrofluoric acid and fluoride compounds. According to some data, zirconium structure does not allow etching which leads to application of different type of primers for increasing the shear strength. Studies show that silane application significantly improves the shear bond strength to the cement, as well as, zirconium tensile strength. Optimal results are registered with a combination of treatment with mechanical methods and silane application.

Conclusion: Preliminary mechanical and chemical treatment of zirconia surface improves the shear bond strength considerably to the cement. The variety of surface treatment methods complicates the establishment of a standard protocol for fixation of zirconium prosthetic constructions.
\end{abstract}

Keywords: zirconia ceramics, cement for zirconium dioxide ceramics.

\section{BACKGROUND}

Modern concept for aesthetic prosthetic treatment motivates the wide application of ceramic materials in dentistry [1]. Their main advantages refer to the enhanced ability to reach a high level of aesthetic and good biological tolerance [2]. They are commonly used to the fabrication of crowns, bridges and indirect restorations- inlays, onlays, overlays [3]. Their manufacturing through modern laboratory technologies allows the achievement of optimal occlusal and approximal contacts in the restoration of frontal and distal teeth [3]. The main disadvantages of ceramic materials are related to their mechanical properties and resistance [4]. This led to the development of new zirconia ceramics which have high flexural strength and fracture resistance [5]. The basis for these improved mechanical properties is yttriastabilized tetragonal zirconia polycrystals (Y-TZP) which are applied in different percentage ratios [6]. Research findings indicate the stability of the crystal structure and high flexure strength, which can reach $2000 \mathrm{Mpa}$ [7]. This provides significantly higher durability of the prosthetic constructions, compared to lithium disilicate ceramic and high-strength glass-ceramic, infiltrated with leucite [8]. The main difference is found with respect to the flexural strength, which is considerably higher in comparison to other ceramics [9]. Zirconia materials (IPS e.max ZirCAD) have 60-70\% higher fatigue resistance compared to lithium disilicate (IPS e.max Press) [10]. Studies show that increased mechanical properties of zirconium dioxide do not cause an abrasive effect on antagonists [11].

The main problems in the application of zirconium materials are related to its transparency and providing of a strong bond to the cement [6]. The assurance of reliable bond strength has a key role in treatment efficacy, as it requires the development of different techniques and methods for preparation and fixation of the prosthetic constructions [12].

\section{AIM}

This literature review analyses the possibilities for improvement of the bond strength between zirconia ceramics and different types of cement which are used for fixation of prosthetic constructions.

\section{REVIEW RESULTS}

Studies show that treatment of the ceramic surface significantly increases the bond strength to the cement [13]. In this context, Comba A. et al. [14] conduct surface treatment 
with diamond burs and demonstrate that it provides better bond in comparison to Er: YAG lasers treatment. Studies by Gamal AE et al. [15] show that laser surface treatment of lithium disilicate (Emax CAD) and zirconium ceramics (Emax ZirCAD) increases the shear bond strength. Data reveal that the application of Er, Cr-YSGG lasers in low power of 2,0 W, increases shear bond strength near to the value when the silicon dioxide bond is applied [16]. According to another study, treatment with $\mathrm{CO}_{2}$ laser increases microhardness of lithium disilicate (Emax CAD) with 6.32
$\mathrm{GPa}$, whereas the application of Nd-YAG laser in zirconia materials reduces microhardness with $1.46 \mathrm{GPa}$ [17].

\section{SURFACE}

CHEMICAL TREATMENT OF THE CERAMIC

Additional chemical treatment is required in order to provide stable adhesion between ceramic materials and cement. Acid-sensitive ceramics, such as feldspath ceramic, leucite and lithium disilicate ceramic allow etching which provides micromechanical retentive surface (table 1).

Table 1: Some types of ceramics used in dentistry

- Feldspath ceramic (Vita Cerec, Dicor)

- Leucite ceramic (leucite-reinforced pressed ceramic)

- Lithium disilicate ceramic (IPS e-max Press, IPS e-max CAD)

- Stabilized zirconia ceramics - Y-TZP (Yttrium tetragonal zirconia polycristal, 2\%-3\% of mol yttria $\mathrm{Y}_{2} \mathrm{O}_{3}$ )

IPS e-max ZirCAD

Structural analysis of etching surface shows differences depending on concentration, time of application and the type of the etching agent - hydrofluoric acid (HF), ammonium bifluoride (ABF), acid phosphate fluoride (APF) [18]. Studies show the efficiency of hydrofluoric etching in lithium disilicate ceramic when combined with silane for optimal shear bond strength [19]. This technique is defined as an optimum protocol, and research findings show stable adhesion even after thermocycling [20]. Etching with hydrofluoric acid, as well as, silane application of leucite-reinforced ceramic increase the adhesion to the glass-ionomer types of cement as well [21]. Nevertheless, studies find that etching the zirconium ceramic with $9,6 \%$ hydrofluorid acid (HF) does not provide effective adhesion [18, 22]. Similar data are accessed by Özcan M et Vallittu PK [23] when treating zirconia-reinforced alumina ceramics (In-Ceram Zirconia). They explain the development with low quantity of glass phase. The scholars measure 8.1 MPa shear bond strength in etching with HF, 16.5 $\mathrm{MPa}$ in sandblasting with alumina oxide and 17.4 MPa in Rocatec system treatment. Studies by Ruyter EI et al. [24] show that better adhesion to the zirconia can be achieved through etching with fluoride compounds (Ammonium hydrogen difluoride, potassium hydrogen difluoride) and silane application. According to others [25], zirconium structure cannot be etched, which requires the use of primers for better shear bond strength. Nakayama D et al. [26] examine the primer effect on the bond strength to the yttria-stabilized zirconia (Katana, Noritake Dental Supply). Zirconia disks are treated with primers Acryl Bond (Shofu), All Bond II Primer B (Bisco), Alloy Primer (Kuraray), Estenia Opaque Primer (Kuraray), Eye Sight Opaque Primer (Kanebo), M.L. Primer (Shofu), MR. Primer (Tokuyama Dental) and Super-Bond liquid (Sun Medical) with Tri-n-butylborane (TBB). The measured shear bond strength varies from $0.7 \mathrm{MPa}$ to $30.8 \mathrm{MPa}$ before and from 0.3 MPa to 17.6 MPA after thermocycling. The highest value is observed in the case of Alloy Primer and Estenia Opaque Primer, which can be explained with the presence of 10-Methacryloyloxydecyl dihydrogen phosphate (MDP) in their composition. The research findings by Torabi Ardakani M. et al. [27] have similar results. They prove that zirconia primer, which is based on organophosphate/carboxylic acid monomers, increases shear bond strength. The opinion of Murakami T. et al. [28] is the opposite. They apply zirconia primer, which contains Tetra-n-propyl zirconate, and report higher shear bond strength in comparison to the MDP ceramic bond.

The aim for improving primers' efficiency is the reason for the inclusion of bisphenol A-glycidyl methacrylate (BisGMA) in their composition. Studies show that it does not affect phosphate-based zirconia primers; however, it reduces the efficiency of silicone primers [29]. Wang C et al. [30] consider that even application of zirconia primer followed by drying with pressured air of $0.2 \mathrm{MPa}$ enhances bond stability. Others recommend preliminary cleaning of zirconia surface with chemical agent and bond application which increase shear bond strength during the initial 24 hours [31].

Kim SM et al. [32] conduct a comparative study of shear bond stability between zirconia and resin types of cement with and without primer application. The cement varieties Panavia F2.0 (P), Panavia F2.0 with primer PRIME Plus (Bisco Inc) (PZ), Superbond (S) and Superbond C\&B with SZ primer are included in the research. The measured values from $265,15 \pm 35,04 \mathrm{~N}(\mathrm{P})$, $318,21 \pm 22,24 \mathrm{~N}(\mathrm{PZ}), 445,13 \pm 78,54 \mathrm{~N}(\mathrm{~S})$ and 508,21 $\pm 79,48 \mathrm{~N}$ (SZ) show significant higher bond strength in Superbond when compared to Panavia F2.0.

\section{OXIDE}

SURFACE TREATMENT WITH ALUMINUM

Other methods of zirconia ceramics surface treatment include aluminum oxide sandblasting for better micromechanical retention. However, studies by Dérand P et Dérand T. [22] show that this has a very weak effect 
on bond strength. Tostes BO et al. [33] do not support this opinion. They treat yttria-stabilized ceramics (Y-TZP) with air abrasion with different size of $\mathrm{Al}_{2} \mathrm{O}_{3}$ particles and conclude that air abrasion leads to phase transformation, increases roughness and transforms Y-TZP elementary compound irrespectively of particles' type or size. Nevertheless, comparative research demonstrates optimal results in the application of $\mathrm{Al}_{2} \mathrm{O}_{3}$ with particles of 50 ìm which provides $50.5 \mathrm{MPa}$ shear bond strength in comparison to 33.1 $\mathrm{MPa}$ when zirconia primer is applied [34]. Studies by
Chen L [35] show that sandblasting with aluminum oxide increases the bond strength, the silane application does not affect it, whereas the use of organophosphate/ carboxylic based primer (Exp Z-Prime) doubles the strength. Inokoshi $\mathrm{M}$ et al. [36] demonstrate that preliminary treatment with silicon dioxide of system CoJet (3M ESPE) together with the application of resin types of cement containing 10-Methacryloyloxydecyl dihydrogen phosphate deliver permanent bond between zirconia and the cement (table2).

\section{Table 2: Suggested treatment of internal ceramic surface}

\begin{tabular}{|l|l|}
\hline Ceramic surface treatment & $\begin{array}{l}\text { Cleaning of the ceramic surface - application for } \\
20 \text { seconds, washing and drying } \\
\text { - Roughened with diamond bur }\end{array}$ \\
- Acid etching $(9.6 \%$ hydrofluorid acid) & $\begin{array}{l}\text { - ZirClean } \\
\text { - Sandblasting with } \mathrm{Al}_{2} \mathrm{O}_{3}(50 \mu \mathrm{m})\end{array}$ \\
- Laser treatment $\left(\mathrm{Er}, \mathrm{Cr}-\mathrm{YSGG}, \mathrm{CO}_{2}, \mathrm{Nd}-\mathrm{YAG}\right)$ & Ultrasound \\
\hline
\end{tabular}

\section{SURFACE}

SILANE TREATMENT OF THE CERAMIC

Most authors [37, 38, 39] consider that silane application significantly increases the bond between the ceramic surface and resin composite cement through the creation of the stable chemical connection. The application of silane ( $\mathrm{SC}$-Cojet, 3M-Espe) increases the shear bond strength to the cement and tensile strength in zirconia-reinforced glass-ceramics (IZ-Vita In-Ceram Zirconia) [38]. Chai J et al. [39] investigate the surface treatment effect when tribochimic silicon coat (silane compound) is applied. They study shear bond strength in
12 models of zirconia (YZ Zirconia) and zirconia glassceramic (In-Ceram Zirconia) which is divided into three groups - without surface treatment (control group), silane system CoJet and laboratory system Rocatac for tribochimic silane coating. Findings show shear bond strength values for In-Ceram Zirconia (control group) of $5,7 \pm 4,3 \mathrm{MPa}$, CoJet $-11,4 \pm 5,4 \mathrm{MPa}$ and Rocatec $-6,5$ $\pm 4,8 \mathrm{MPa}$. Respectively, the measured values in the case of the YZ zirconia are 8,2 $\pm 5,4 \mathrm{MPa}, 9,8 \pm 5,4 \mathrm{MPa}$ and 7,8 \pm 4,7 MPa. Researchers suggest that silane coating can significantly improve the bond strength between resin composite cement and In-Ceram Zirconia (table 3).

Table 3: Silane treatment of the ceramic surface

- Silane coupling - 10Methacryloyloxydecyl dihydrogen phosphate (MDP), Z-Prime, Monobond Plus

- Tribochemical coating - CoJet (with $\mathrm{SiO}_{2}$ )

According to Siwen L et al. [40], aluminum oxide sandblasting followed by silicon oxide coating is the most effective technique for increasing the bond strength between zirconia ceramic and the dentin. Lung CY et al. [41] consider that modern silane products are far from being a perfect solution; however, they can fulfill the minimum requirements for improving bond strength to the zirconia. Researchers conclude that further studies and development of new methods are necessary in order to overcome the problem with adhesion durability.

There are different studies assessing the surface treatment effect on the bond strength. Shin YJ et al. [42] investigate shear bond strength of Y-TZP (Yttria-Tetragonal Zirconia Polycrystal ceramic and resin composite types of cement with 10-Methacryloyloxydecyl dihydrogen phosphate (MDP). Zirconia blocks (LAVA, 3M ESPE, St. Paul, MN) are distributed in five groups depending on the conducted surface treatment: (1) without any additional surface treatment (control group); (2) sandblasting with $\mathrm{Al}_{2} \mathrm{O}_{3}$ particles; (3) conditioning with primer $\mathrm{Z}$ -
PRIME Plus (Bisco, Schaumburg, IL), applied on polished zirconia; (4) primer Z-PRIME Plus after sandblasting and (5) tribochimic coating with silicon dioxide on the CoJet system (3M ESPE). Two composite types of cement are used per each group - Panavia F2.0 (Kuraray, Kurashiki, Okayama, Japan) and Clearfil SA Luting (Kuraray). Findings indicate that primers significantly increase bond strength in relation to both types of cement when the former is applied after abrasion. The control group has the lowest value of shear bond strength.

Keshvad A and Hakimaneh SMR [43] study the effects of different surface treatment on the shear bond strength between composite cement with lithium and zirconia ceramics. The zirconia samples (IPS e.max ZirCAD) are sandblasted + silane (ZiSa); sandblasted + laser + silane (ZiSaLa); laser + silane (ZiLa). The lithium disilicate ceramics (IPS e.max CAD) are: sandblasted + HF + silane (LiSaE); sandblasted + silane ( $\mathrm{LiSa})$; sandblasted + laser + silane (LiSaLa). The study reports no significantly significant difference between LiSaE and LiSa test 
groups $(p>0,05)$; however, there are statistically significant differences between $\mathrm{ZiSaLa}$ and $\mathrm{ZiSa}$ groups ( $\mathrm{p}>$ $0,05)$. Laser treated test groups have lower values of shear bond strength in comparison to the other ones.

Sakrana AA and Özcan M. [44] study the adhesion of self-adhesive cement (RelyX Unicem Aplicap, 3M ESPE) to the zirconia (IPS e.max ZirCAD, Ivoclar Vivadent) after different surface treatment methods: C: without surface treatment (control group); AS: air abrasion $\left(50 \mu \mathrm{m} \mathrm{Al}_{2} \mathrm{O}_{3}\right)$ in low pressure (0.2MPa) and silane application (Monobond Plus, Ivoclar Vivadent); MC: methylene chloride treatment for 60 seconds; CE: solution for chemical treatment for 60 seconds in $100^{\circ} \mathrm{C}$. The highest surface abrasion is achieved in group $\mathrm{CE}(0,52 \mu \mathrm{m})$ and the lowest one in group $\mathrm{C}(0,25$ $\mu \mathrm{m})$. The weakest bond strength is registered in group $\mathrm{C}$ $(5.11 \pm 0.5 \mathrm{MPa})$ in comparison to the rest test groups where the values vary from $34.6 \pm 1.5$ to $51.2 \pm 1.1 \mathrm{Mpa}$. The highest shear bond strength is registered in group CE - 51,2 $\pm 1,1 \mathrm{MPa}$. The authors view chemical etching as a successful substitute for air abrasion.

Bielen $\mathrm{V}$ et al. [45] analyze the efficiency of adhesion to the zirconia with different surface treatment. IPS e.max ZirCAD (Ivoclar Vivadent) ceramics are divided into four groups: (1) samples without surface treatment; (2) sandblasted with $50 \mu \mathrm{m} \mathrm{Al} \mathrm{O}_{3}$, (3) tribochimic sandblasting with silicon dioxide (CoJet-3M ESPE) and (4) silicon dioxide treatment SilJet (Danville). After processing, the blocks are treated with 10-MDP/silane ceramic primer (Clearfil Ceramic Primer, Kuraray Noritake) and fixed to each other with resin composite cement (RelyX Ultimate, $3 \mathrm{M}$ ESPE). Then, the shear bond strength test is performed. The accessed results show the highest bond strength, where silicon dioxide (CoJet, SilJet) sandblasting method is applied.

Baldissara P et al. [46] conduct a similar study and investigate shear bond strength (SBS) between two types of cement (Panavia F è RelyX Unicem) and two Y-TZP ceramics (Lava and ZirCAD) subjected to different surface treatment: without surface treatment (control group); silicon dioxide sandblasting ( $30 \mu \mathrm{m}$, CoJet Sand) or coating with liners Lava Ceram for Lava and Intensive ZirLiner for IPS e.max ZirCAD. Findings show the most stable bond strength when CoJet Sand and liners are applied.

Stefani A et al. [47] measure the shear bond strength of different types of resin composite cement (RelyX ARC, Multilink Automix, Clearfil SA) to zirconia ceramics by applying two primers (Metal-Zirconia Primer, Alloy Primer). The study is conducted based on 50 zirconia blocks (ZirCad) with the size of $12 \mathrm{~mm} \times 5 \mathrm{~mm} \times 1,5 \mathrm{~mm}$ thickness which is sandblasted with aluminum dioxide particles and cleaned by ultrasound. The primers and types of cement are applied in accordance with the manufacturer's instructions. Conventional resin composite cement RelyX ARC without primer is used as a control group. Finding show shear bond strength equal to $28.1 \mathrm{MPa}$ in RelyX ARC; Multilink Automix - 37.6 MPa; Multilink Automix + Metal-Zirconia Primer - 55.7 MPa; Clearfil SA - 46.2 MPa and Clearfil SA cement + primer - 47.0 MPa.

The development of new zirconia-based materials requires the application of advanced types of cement [48, 49, 50]. Passia N et al. [51] conduct laboratory experiments in order to assess tensile strength of three new generations of universal adhesion systems to the zirconia ceramics (Max ZirCAD) - Monobond Plus/Multilink Automix, NX3, Scotchbond Universal/RelyX Ultimate. Findings show an average bond strength of 21.7-28.8 $\mathrm{MPa}$ in RelyX Ultimate, with and without Scotchbond Universal and substantially lower values from 15.4 MPa in Monobond Plus/Multilink Automix. The weakest strength value is reported in NX3 - 6.6MPa.

Salem RST [52] studies the shear bond strength (SBS) between the cement and zirconia before and after thermocycling. Sandblasted discs of monolithic zirconia $(10 \times 3 \mathrm{~mm})$ are used as samples. The specimens are divided into three groups according to the applied adhesive system: Z-PRIME Plus/ DUO-LINK (Bisco); Clearfil Ceramic Primer Plus/PANAVIA SA (Kuraray); Universal bond/RelyX Ultimate (Single Bond) (3M ESPE). The highest and lowest values are measured in the systems Kuraray $(12.52 \pm 1.34 \mathrm{MPa})$ and Bisco $(5.32 \pm 0.54 \mathrm{MPa})$ in thermocycler groups $(\mathrm{P}<.05)$. Kuraray has the highest $(16.47 \pm 1.5 \mathrm{MPa})$ and Bisco the lowest $(7.43 \pm 1.06 \mathrm{MPa})$ $\mathrm{SBS}$ values in the short-term storage groups $(\mathrm{P}<.05)$. The author concludes that thermocycling reduces SBS significantly with respect to all test groups and recommends the use of resin composite types of cement with Methacryloyloxydecyl dihydrogen phosphate for permanent adhesion to the zirconia.

\section{DISCUSSION}

There are numerous studies from the available literature focused on examining the bond strength between zirconia ceramics and different type of cement. The conclusion that preliminary zirconia surface treatment increases the strength and durability of fixation is unanimous. Different methods and means are used for this purpose. Some authors recommend only mechanical treatment with diamond burs, a different type of lasers and aluminum dioxide sandblasting. The data about these methods' efficiency are controversial, as the most serious variations exist regarding the type and power of lasers. Most authors suggest that sandblasting with aluminum dioxide is an optimal method for mechanical treatment of the zirconia surface and good micromechanical retention. Comparative studies show the achievement of best results when 50 ìm $\mathrm{Al}_{2} \mathrm{O}_{3}$ particles are used [33, 44, 45].

Other methods for creation of stable adhesion between zirconia ceramic and cement are chemical agents for surface treatment, such as hydrofluoric acid of fluoride compounds. Data determine this as an ineffective treatment method, which is explained by the specifics of zirconia structure. This requires coating with primers for increasing the adhesion to the cement. Some authors recommend primers with 10-Methacryloyloxydecyl dihydrogen phosphate (MDP), while others suggest tetran-propoxyl zirconate (TPZr).

Research findings show that the combination of mechanical treatment methods followed by the applica- 
tion of bonding agent significantly increase the bond strength to the cement. According to some data, sandblasting with aluminum dioxide followed by silicon dioxide coating is the most effective technique for increasing the bond strength between zirconia ceramics and the cement. Others claim that the strongest adhesion is created after sandblasting with silicon dioxide (CoJet, SilJet) and silane coating. Irrespectively of the controversial information, the consensus opinion shows that the combined technique of mechanical treatment and silane application increase the bond strength.

There are numerous studies regarding the application of different cement in fixed prosthetic treatment. The dominant opinion suggests that silane coating provides a stable chemical connection between the ceramic surface and composite cement; thereby, increasing the bond strength $[37,38,39]$. Research findings show that preliminary treatment with silicon dioxide with CoJet (3M ESPE) system combined with resin composite cement with 10Methacryloyloxydecyl dihydrogen phosphate provide permanent adhesion of zirconia to the cement. Due to the diversity of cement there are various, often conflicting data on their efficiency and durability.

\section{CONCLUSION}

The analysis of the literature review demonstrates that there are no universal methods, techniques or materials for fixing zirconia constructions. Findings unequivocally show that preliminary mechanical and chemical treatment of zirconia surface significantly improves the shear bond strength. There are diverse and often conflicting opinions regarding the choice of the optimum treatment method for zirconia surface preparation. The variety of cement further complicates the selection and creation of a standard clinical protocol for working with this type of ceramic.

The study is financed by the Medical Science Council of Medical University - Sofia based on the “Grant-2020” programme. Contract Д-107/24.06.2020

\section{REFERENCES:}

1. Santos MJ, Costa MD, Rubo JH, Pegoraro LF, Santos GC. Current allceramic systems in dentistry: a review. Compend Contin Educ Dent. 2015 Jan;36(1):31-7. [PubMed]

2. McLaren EA, Figueira J. Updating Classifications of Ceramic Dental Materials: A Guide to Material Selection. Compend Contin Educ Dent. 2015 Jun;36(6):400-5. [PubMed]

3. Spitznagel FA, Boldt J, Gierthmuehlen PC. CAD/CAM Ceramic Restorative Materials for Natural Teeth. J Dent Res. 2018 Sep;97(10):1082-91. [PubMed]

4. Kelly JR, Benetti P. Ceramic materials in dentistry: historical evolution and current practice. Aust Dent J. 2011 Jun;56(1):84-96. [PubMed]

5. Butt K, Thanabalan N, Ayub K, Bourne G. Demystifying Modern Dental Ceramics. Prim Dent J. 2019 Nov;8(3):28-33. [PubMed]

6. Prasad HA, Pasha N, Hilal M, Amarnath GS, Kundapur V, Anand M, et al. To Evaluate Effect of Airborne Particle Abrasion using Different Abrasives Particles and Compare Two Commercial Available Zirconia on Flexural Strength on Heat Treatment. Int J Biomed Sci. 2017 Jun;13(2):93112. [PubMed]

7. Gautam C, Joyner J, Gautam A, Rao J, Vajtai R. Zirconia based dental ceramics: structure, mechanical prop- erties, biocompatibility and applications. Dalton Trans. 2016 Dec; 45(48):19194-215. [PubMed]

8. Belli R, Petschelt A, Hofner B, Hajtó J, Scherrer SS, Lohbauer U. Fracture Rates and Lifetime Estimations of CAD/CAM All-ceramic Restorations. $J$ Dent Res. 2016 Jan;95(1):67-73. [PubMed]

9. Alessandretti R, Ribeiro R, Borba M, Bona AD. Fracture Load and Failure Mode of CAD-on Ceramic Structures. Braz Dent J. 2019 Jul; 30(4):380-4. [PubMed]

10. Heintze SD, Monreal D, Reinhardt M, Eser A, Peschke A, Reinshagen J, et. al. Fatigue resistance of all-ceramic fixed partial dentures Fatigue tests and finite element analysis. Dent Mater. 2018 Mar;34(3):494507. [PubMed]

11. Kontos L, Schille C, Schweizer E, Geis-Gerstorfer J. Influence of surface treatment on the wear of solid zirconia. Acta Odontol Scand. 2013 May-Jul;71(3-4):482-7. [PubMed]

12. Al-Harbi FA, Ayad NM, Khan ZA, Mahrous AA, Morgano SM. In vitro shear bond strength of Y-TZP ceramics to different core materials with the use of three primer/resin cement systems. J Prosthet Dent. 2016 Jan;115(1):84-9.

13. Ataol AS, Ergun G. Effects of surface treatments on repair bond strength of a new CAD/CAM ZLS glass ceramic and two different types of CAD/CAM ceramics. J Oral Sci. 2018;60(2):201-11. [PubMed]

14. Comba A, Baldi A, Michelotto Tempesta R, Cedrone A, Carpegna G, Mazzoni A, et al. Effect of Er:YAG and Burs on Coronal Dentin Bond Strength Stability. J Adhes Dent. 2019; 21(4):329-35. [PubMed]

15. Gamal AE, Medioni E, Rocca JP, Fornaini C, Brulat-Bouchard N. $\mathrm{CO}_{2}$ laser dentin surface treatment most effectively increased ceramic shear bond strength. Laser Ther. 2018 Mar;27(1):48-54. [PubMed]

16. Zeidan LC, Esteves CM, Oliveira JA, Brugnera A Jr, Cassoni A, Rodrigues JA. Effect of different power settings of Er,Cr:YSGG laser before or after tribosilicatization on the microshear bond strength between zirconia and two types of cements. $\mathrm{La}$ sers Med Sci. 2018 Feb;33(2):233-40. [PubMed]

17. El Gamal A, Rocca JP, Fornaini C, Medioni E, Brulat-Bouchard N. Microhardness evaluations of CAD/ CAM ceramics irradiated with $\mathrm{CO}_{2}$ or Nd:YAP laser. Laser Ther. 2017 Mar; 26(1):13-18. [PubMed]

18. Della Bona A, Anusavice KJ. Microstructure, composition, and etching topography of dental ceramics. Int J Prosthodont. 2002 Mar-Apr; 


\section{5(2):159-67. [PubMed]}

19. Lopes GC, Perdigão J, Baptista D, Ballarin A. Does a Self-etching Ceramic Primer Improve Bonding to Lithium Disilicate Ceramics? Bond Strengths and FESEM Analyses. Oper Dent. 2019 Mar-Apr; 44(2):210-18. [PubMed]

20. Lee HY, Han GJ, Chang J, Son $\mathrm{HH}$. Bonding of the silane containing multi-mode universal adhesive for lithium disilicate ceramics. Restor Dent Endod. 2017 May;42(2):95-104. [PubMed]

21. Kim RJ, Woo JS, Lee IB, Yi YA, Hwang JY, Seo DG. Performance of universal adhesives on bonding to leucite-reinforced ceramic. Biomater Res. 2015 May;19:11. [PubMed]

22. Dérand P, Dérand T. Bond strength of luting cement to zirconium oxide ceramics. Int J Prosthodont. 2000 Mar-Apr;13(2): 131-5. [PubMed]

23. Özcan M, Vallittu PK. Effect of surface conditioning methods on the bond strength of luting cements to ceramics. Dent Mater. 2003 Dec; 19(8):725-31. [PubMed]

24. Ruyter EI, Vajeeston N, Knarvang T, Kvam K. A novel etching technique for surface treatment of zirconia ceramics to improve adhesion of resin-based luting cements. Acta Biomater Odontol Scand. 2017 Apr;3(1):36-46.

25. Afrasiabi A, Mostajir E, Golbari $\mathrm{N}$. The effect of Z-primer on the shear bond strength of zirconia ceramic to dentin: in vitro. J Clin Exp Dent. 2018 Jul;10(7):661-4. [PubMed]

26. Nakayama D, Koizumi $H$, Komine F, Blatz MB, Tanoue N, Matsumura H. Adhesive bonding of zirconia with single-liquid acidic primers and a tri-n-butylborane initiated acrylic resin. J Adhes Dent. 2010 Aug;12(4):305-10.

27. Torabi Ardakani M, Giti R, Taghva M, Javanmardi S. Effect of a zirconia primer on the push-out bond strength of zirconia ceramic posts to root canal dentin. J Prosthet Dent. 2015 Sep;114(3):398-402. [PubMed]

28. Murakami T, Takemoto $\mathrm{S}$, Nishiyama N, Aida M. Zirconia surface modification by a novel zirconia bonding system and its adhesion mechanism. Dent Mater. 2017 Dec;

\section{3(12):1371-80. [PubMed]}

29. Chen L, Shen H, Suh BI. Effect of incorporating BisGMA resin on the bonding properties of silane and zirconia primers. J Prosthet Dent. 2013 Nov;110(5):402-7. [PubMed]

30. Wang C, Niu LN, Wang YJ, Jiao $\mathrm{K}$, Liu Y, Zhou W, et. al. Bonding of resin cement to zirconia with high pressure primer coating. PLoS One. 2014 Jul;9(7):101174. [PubMed]

31. Negreiros WM, Ambrosano GMB, Giannini M. Effect of cleaning agent, primer application and their combination on the bond strength of a resin cement to two yttrium-tetragonal zirconia polycrystal zirconia ceramics. Eur J Dent. 2017 Jan-Mar; 11(1):6-11. [PubMed]

32. Kim SM, Yoon JY, Lee MH, Oh NS. The effect of resin cements and primer on retentive force of zirconia copings bonded to zirconia abutments with insufficient retention. $J A d v$ Prosthodont. 2013 May;5(2): 198-203. [PubMed]

33. Tostes BO, Guimarães RB, Noronha-Filho JD, Botelho GD, Guimarães JG, Silva EM. Characterization of Conventional and High-Translucency Y-TZP Dental Ceramics Submitted to Air Abrasion. Braz Dent J. 2017 Jan-Feb;28(1):97-104. [PubMed]

34. Sanlэ S, Çömlekoglu MD, Çömlekoglu E, Sonugelen M, Pamir T, Darvell BW. Influence of surface treatment on the resin-bonding of zirconia. Dent Mater. 2015 Jun;31(6): 657-68. [PubMed]

35. Chen L, Suh BI, Kim J, Tay FR. Evaluation of silica-coating techniques for zirconia bonding. Am J Dent. 2011 Apr;24(2):79-84.

36. Inokoshi M, Poitevin A, De Munck J, Minakuchi S, Van Meerbeek B. Bonding effectiveness to different chemically pre-treated dental zirconia. Clin Oral Investig. 2014 Sep;18(7):1803-12. [PubMed]

37. Smith RL, Villanueva C, Rothrock JK, Garcia-Godoy CE, Stoner BR, Piascik JR, et. al. Longterm microtensile bond strength of surface modified zirconia. Dent Mater. 2011 Aug;27(8):779-85. [PubMed]

38. Della Bona A, Borba M, Benetti P, Cecchetti D. Effect of surface treatments on the bond strength of a zirconia-reinforced ceramics to composite resin. Braz Oral Res. 2007 Jan-Mar;21(1):10-5. [PubMed]

39. Chai J, Chu FC, Chow TW. Effect of surface treatment on shear bond strength of zirconia to human dentin. J Prosthodont. 2011 Apr; 20(3):173-9. [PubMed]

40. Siwen L, Shishi L, Yanhong W, Hongmei M. [Effects of different surface modifications on micro-structure and adhesion of zirconia ceramic: an in vitro study.] [in Chinese] Hua Xi Kou Qiang Yi Xue Za Zhi. 2017 Feb 1;35(1):43-50. [PubMed]

41. Lung CYK, Matinlinna JP. Aspects of silane coupling agents and surface conditioning in dentistry: an overview. Dent Mater. 2012 May; 28(5):467-77. [PubMed]

42. Shin YJ, Shin Y, Yi YA, Kim J, Lee IB, Cho BH, et. al. Evaluation of the shear bond strength of resin cement to Y-TZP ceramic after different surface treatments. Scanning. 2014 Sep-Oct;36(5):479-86. [PubMed]

43. Keshvad A, Hakimaneh SMR. Microtensile Bond Strength of a Resin Cement to Silica-Based and Y-TZP Ceramics Using Different Surface Treatments. J Prosthodont. 2018 Jan; 27(1):67-74. [PubMed]

44. Sakrana AA, Özcan M. Effect of chemical etching solutions versus air abrasion on the adhesion of self-adhesive resin cement to IPS e.max ZirCAD with and without aging. Int $J$ Esthet Dent. 2017;12(1):72-85. [PubMed]

45. Bielen V, Inokoshi M, Munck JD, Zhang F, Vanmeensel K, Minakuchi S, et. al. Bonding Effectiveness to Differently Sandblasted Dental Zirconia. J Adhes Dent. 2015 Jun;17(3):235-42. [PubMed]

46. Baldissara P, Querzè M, Monaco C, Scotti R, Fonseca RG. Efficacy of surface treatments on the bond strength of resin cements to two brands of zirconia ceramic. J Adhes Dent. 2013 Jun;15(3):259-67. [PubMed]

47. Stefani A, Brito RB Jr, Kina S, Andrade OS, Ambrosano GM, Carvalho AA, et. al. Bond Strength of Resin Cements to Zirconia Ceramic Using Adhesive Primers. $J$ Prosthodont. 2016 Jul;25(5):380-5. [PubMed]

48. Anastasov I. (Editor). [Dental 
material science.] [in Bulgarian] 2nd edition, Smile Center, Sofia. 2017: 286-303.

49. Anastasov I. (Editor), Yoshida Y. [800 Tests in Dental Materials Science.] [in Bulgarian] Smile Center, Sofia. 2013:12-28.

50. Stoeva D, Gerdzhikov I. Advan- tages and disadvantages of modern glass carbomer cements. World J Pharm Pharm Sci. 2018 Nov;7(11):53-60.

51. Passia N, Mitsias M, Lehmann F, Kern M. Bond strength of a new generation of universal bonding systems to zirconia ceramic. J Mech Behav Biomed Mater. 2016 Sep;

\section{2:268-74. [PubMed]}

52. Salem RST, Ozkurt-Kayahan Z, Kazazoglu E. In Vitro Evaluation of Shear Bond Strength of Three Primer/ Resin Cement Systems to Monolithic Zirconia. Int J Prosthodont. 2019 NovDec;32(6): 519-25. [PubMed]

Please cite this article as: Gerdzhikov I, Radeva E, Uzunov T. Possibilities of Improving the Shear Strength Between Different Type of Cement and Zirconia Ceramics: Literature Review. J of IMAB. 2021 Jan-Mar;27(1):3557-3563.

DOI: https://doi.org/10.5272/jimab.2021271.3557

Received: 28/03/2020; Published online: 26/01/2021

Address for correspondence:

Dr Ivan Gerdzhikov

Department of Prosthetic Dental Medicine, Faculty of Dental Medicine, Medical University - Sofia

1, St. George Sofiyski Blvd., 1431 Sofia, Bulgaria

e-mail: ivan_ger1971@abv.bg 